\title{
Medidas de difusividade térmica por meio de um sensor PZT
}

\section{Anderson R. Cinti *, Antonio M. Mansanares.}

\section{Resumo}

Neste projeto realizamos um estudo sobre o uso da técnica fotoacústica para a medida da difusividade térmica em sólidos. Em particular, analisamos o emprego de um sensor PZT(titanato- zirconato de chumbo) para a medida da variação da temperatura na amostra após a absorção de um feixe laser modulado em intensidade. A equação de difusão do calor em uma dimensão foi resolvida para um ou mais meios, de forma a descrever a amostra, o sensor e o suporte. Foram realizados cálculos do perfil de temperatura nos meios para diversos valores da difusividade térmica, da condutividade térmica e da frequência de modulação. Medidas iniciais foram feitas com o objetivo de caracterizar o sensor.

\section{Palavras-chave:}

Fotoacústica, difusividade térmica, piezoeletricidade.

\section{Introdução}

Materiais PZT's são sensíveis a variações de pressão e de temperatura, ou seja, são piezoelétricos e piroelétricos. ${ }^{1-4}$ São, portanto, capazes de detectar pequenas variações de temperatura induzidas numa amostra pela absorção de um feixe laser.

A difusividade térmica é o parâmetro de transporte que governa a propagação do calor num meio em situações transientes. É o que ocorre quanto um pulso de feixe laser é absorvido em uma face da amostra, elevando a temperatura da mesma na região de absorção. O calor é então conduzido dessa região mais quente para as partes de menor temperatura da amostra. Neste processo, a temperatura de cada ponto da amostra aumenta e depois volta a diminuir, fazendo com que, além da condutividade térmica $(k)$, a capacidade térmica $\left(c_{p}\right)$ também esteja envolvida na equação de transporte através da difusividade térmica $\left(\alpha=k / \rho c_{p}\right.$, sendo $\rho$ a densidade).

A determinação da difusividade térmica através da técnica fotoacústica baseia-se na excitação de uma das faces da amostra pela absorção de um feixe laser modulado em intensidade, seguida da medida da temperatura na outra face (amostra em forma de lâmina). A difusividade térmica é determinada a partir da atenuação da elevação da temperatura, ou da defasagem em relação à incidência do laser.

\section{Resultados e Discussão}

A equação de difusão do calor foi resolvida para o caso de absorção do laser na superfície da amostra, com as condições de contorno de continuidade da temperatura e do fluxo de calor nas interfaces entre meios, quando era o caso. A Figura 1(a) mostra a amplitude da elevação da temperatura em função da posição numa amostra infinita, ou seja, com espessura muito maior que o comprimento de difusão térmica $\mu$ ( $x=0$ corresponde à superfície dianteira, onde o laser é absorvido). O parâmetro $\mu$ depende da difusividade térmica e da frequência de modulação do laser, de forma que a medida da temperatura na face traseira da amostra permite a determinação do parâmetro de transporte térmico.

A Figura 1(b) mostra o sinal obtido com excitação direta do sensor PZT em função da frequência de modulação. A comparação do resultado com o cálculo para este caso mostra que o sinal é proporcional à temperatura média no sensor, como esperado.
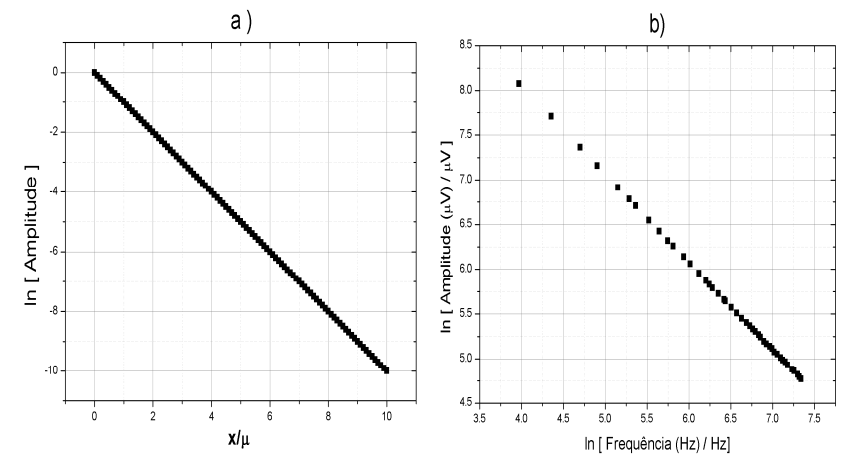

Figura 1. a) Amplitude da temperatura em função da profundidade da amostra. b) Sinal para excitação direta do PZT em função da frequência de modulação.

\section{Conclusões}

A variação dos parâmetros térmicos dos meios considerados nas simulações permite avaliar a sensibilidade da técnica para discriminar estes parâmetros em amostras de interesse.

\section{Agradecimentos}

Os autores agradecem ao CNPq e ao SAE pelo apoio financeiro.

1. http://en.wikipedia.org/wiki/Lead zirconate titanate

2. E. Marin, E. Hernández-Rosales, A. M. Mansanares, R. Ivanov, J. B. RojasTrigos, A. Calderón, Rev. Sci. Instrum. 84, 104903 (2013).

3. J. B. Rojas-Trigos, E. Marin, A. M. Mansanares, E. Cedeno, G. Juarez-Gracia, A. Calderon, Thermochimica Acta 582, 101-105 (2014).

4. A. M. Mansanares, H. Vargas, F. Galembeck, J. Buys, D. Bicanic, J. Appl. Phys., 70 (11), 7046-7050 (1991). 